\title{
Using Climate-Soil-Socioeconomic Parameters For a Drought Vulnerability Assessment in a Semi-Arid Region: Application at the Region of El Hodna, (M'sila, Algeria)
}

\author{
Meriem BoultifA*, Hassen Benmessaoud ${ }^{A}$ \\ Received: March 18, 2017 | Revised: June 5, 2017 | Accepted: June 19, 2017 \\ DOI: $10.5937 / G e o P a n 1703142 B$
}

\begin{abstract}
The objective of this study is to contribute in assessing and monitoring drought's vulnerability by developing a GIS- based model to determine vulnerable areas to this natural hazard; the model utilizes a series of agricultural, statistical, meteorological and remotely sensed data, using GIS weighed ponderation and multicriteria analysis decision making, with the integration of three components: climatic sensibility, soil sensibility and socioeconomic sensibility. The result is a vulnerability map classified into five classes according to pixel values. Very Vulnerable class forms $19.46 \%$ of the study area, vulnerable class forms $32.81 \%$ and $21.37 \%$ of the area is not vulnerable, the study presents a modeling procedure of which the final results provide to researchers, users and decision makers important information on the environmental situation of the study area, for better prediction, and risk management.
\end{abstract}

Keywords: Drought; Modelling; GIS; Multi-criteria Analysis; Vulnerability

\section{Introduction}

Of all natural hazards drought is the most complex and least understood, it affects large numbers of people and results in significant economic, social and environmental impacts (Wilhite, 2005). It does not have a universal definition, but it can be said that drought is a deficit of water availability comparing to normal water supplies during a period of time (Layelmam, 2008), rainfall deficit may occur after a few days, weeks, months or even years which makes it is a very difficult hazard to monitor (Yasef, Saltani, 2009). Drought's intensity is also increased by the adverse human effect on the environment, like deforestation, gas emissions, livestock pressure, overgrazing and the overuse of natural resources (Safar Zitoun, 2006). Drought's evolvement is slow and does not present an instantaneous danger, it aggravates the stress on nat- ural resources (soil and water reserves), and jeopardizes food and water security. The impacts of drought are observed over large area compared to other natural hazards such as floods, tropical storms, and earthquakes, which makes it particularly challenging to quantify the impact (Wilhite, 2005).

Four types of drought are distinguished; the most remarkable type is meteorological drought that which occurs when water deficiency spans an extended period of time (Wilhite, 2005). A hydrological drought is related to water supply diminution in soil and/or subsurface waters (i.e., stream flow, reservoir, lake) (Layelmam, 2008). An agricultural drought begins when the soil moisture available to plants drops to a level that adversely affects the crop yield and agricultural production (Martínez-Fernández, et al., 2015). A socioeconomic drought differs from other types in reflecting

\footnotetext{
A Department of Ecology and Environment, Faculty of Nature and Life Sciences, University of Batna 02, Fesdis, 05110 Batna, Algeria; boultif.meriem05@gmail.com, ha123_m123@yahoo.fr

* Corresponding author: boultif.meriem05@gmail.com
} 
the disequilibrium between the supply and demand of certain natural resources (i.e, potable water) and economic goods (i.e., cereal) (WMO, 2006).

With global warming and the frequent occurrence of extreme events; concerns about global drought and its impacts have become more pronounced in recent years (Dai, 2011), particularly in arid and semi-arid regions where drought vulnerability is related mainly to climatic disturbances. The definition of vulnerability is the degree to which a system is susceptible to climate change and unable to cope with adverse effects (Houghton, et al., 2001).

In order to monitor and assess drought's impact, a series of indices and parameters have been developed to depict drought in different applications (Dracup, et al., 1980; Wilhite, Glantz, 1985). However, drought monitoring systems should be integrated and based on multiple physical and socioeconomic indicators to fully understand it's magnitude, spatial extent, and impacts (Wilhite, 2005). The present study seeks to identify the spatial extent of drought vulnerability in an arid region situated in central Algeria, a country that has experienced severe droughtrelated disasters during the last decades (Bensaid, 2006), the problem of Algerian arid regions' vulnerability made the project of several studies (Nichane,
Khelil, 2014; Medjereb, Henia, 2011; Bensaid , 2006, Nadjraoui , 2011).

The methodology is based on developing a GIS model based on two previous regional drought assessing projects: the DMCSEE (drought monitoring center of southeastern Europe) model presented in 2012 to assess and monitor drought in southeast countries of Europe and the OSS (Sahara and Sahel Observatory) model presented in 2009 to put a classification of drought vulnerable areas of North African countries (Algeria, Morocco and Tunisia).

\section{Methods and data}

\section{Study area}

The study area is situated in central Algeria, in the El Hodna region, ( $4^{\circ} 90^{\prime} 4^{\circ} 351^{\prime} \mathrm{N}$ and $35^{\circ} 87^{\prime} .35^{\circ} 17^{\prime} \mathrm{E}$ ). It spans the area of $1261.20 \mathrm{~km}^{2}$ and extends over 6 sub-divisions (communes) of M'sila province: Maadhid, M'tarfa, M'sila, Souamaa, Ouled madhi and M'cif, (Figure 1), including the salt pan named "Chott El Hodna" (400 $\mathrm{m}$ above sea level).

According to Köppen's climate classification; this region has a steppe arid climate with cold winter (Bsk) (Urlike, et al., 1993). The study area is a typical North

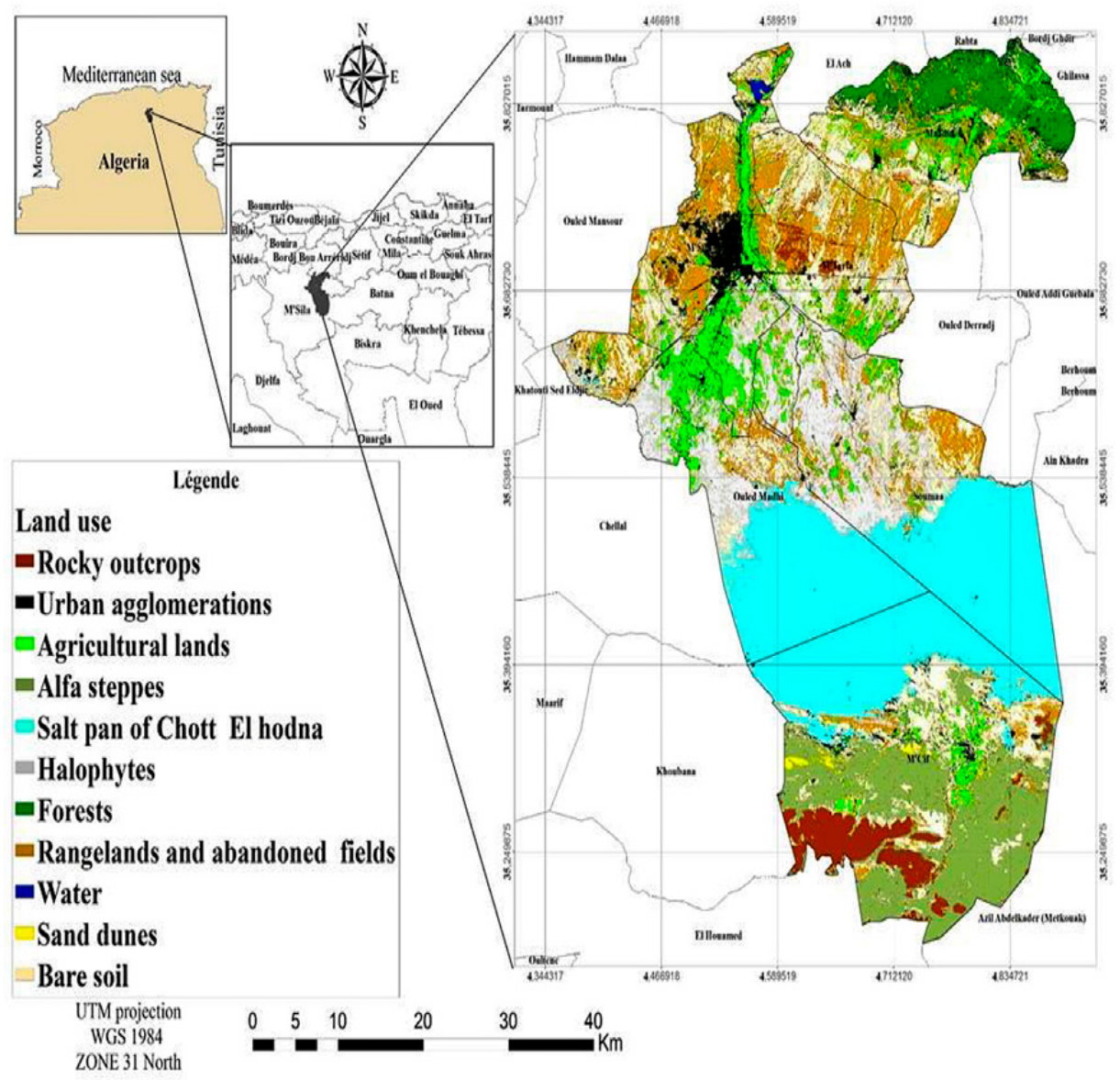

Figure 1. Geographic localization and the land use of the study area 
African arid zone, characterized by a land use variability and heterogeneity; $12.25 \%$ of the study area is covered by rangelands reserved for grazing, $13 \%$ by halophytes surrounding the salt pan of Chott El hodna that constitutes $24.20 \%$ of the area, bare soil forms $19.24 \%$ and alfa (Stippa Tenacissima) forms $10.42 \%$, where agricultural lands cover only $8.56 \%$ and forests cover $3.75 \%$ of the surface.

\section{Data processing}

Drought vulnerability mapping is generally based on calculated inputs that are obtained from thematic maps, remotely sensed images, climate and socioeconomic statistics. Our approach is based on using a series of drought related inputs to build a GIS-based model based on two existing experiences: OSS methodology (Observatory of Sahara and Sahel) and DMCEE methodology (Drought Management Centre for Southeastern Europe).

In 2009 the observatory of Sahara and Sahel (OSS) proposed a GIS model based on the overlay of several weighted factors for mapping drought vulnerability in North African countries (Table 1). This model used aridity, livestock pressure and soil sensibility as parameters to which weights have been assigned by experts according to the importance of each parameter in drought vulnerability (Safar Zitoun, 2006).

The Drought Management Centre for Southeastern Europe (DMCEE) proposed in 2012 a methodology for estimating and drought vulnerability mapping in southeast countries of Europe also based on
Table 1. OSS vulnerability mapping parameters for North African countries

\begin{tabular}{|l|l|c|}
\hline \multicolumn{2}{|l|}{ Parameter } & Weight \\
\hline Aridity & 0.65 \\
\hline Livestock pressure & & 0.22 \\
\hline \multirow{2}{*}{ Soil sensibility } & Water retention capacity & \multirow{2}{*}{0.13} \\
\cline { 2 - 3 } & Soil occupation & \\
\hline
\end{tabular}

the weighted overlay of several spatial layers (Table.2) to conduct an assessment of institutional capacity, including Meta data available by selecting and evaluating the most effective and reliable indices and indicators for drought assessment (Móring, et al., 2012).

Table 2. DMCEE vulnerability mapping parameters and weight for south Eastern Europe countries (2012)

\begin{tabular}{|l|l|}
\hline Parameter & Weight \\
\hline Slope & 0.1623 \\
\hline Available groundwater & 0.0518 \\
\hline Sunshine duration & 0.3071 \\
\hline Precipitation & 0.1180 \\
\hline Land use & 0.0858 \\
\hline Soil type & 0.2232 \\
\hline Irrigation & 0.0518 \\
\hline
\end{tabular}

The contribution of the present study is to propose a methodology based on the previously presented models, the essential objective is to conduct a drought vulnerability assessment by identifying three principal

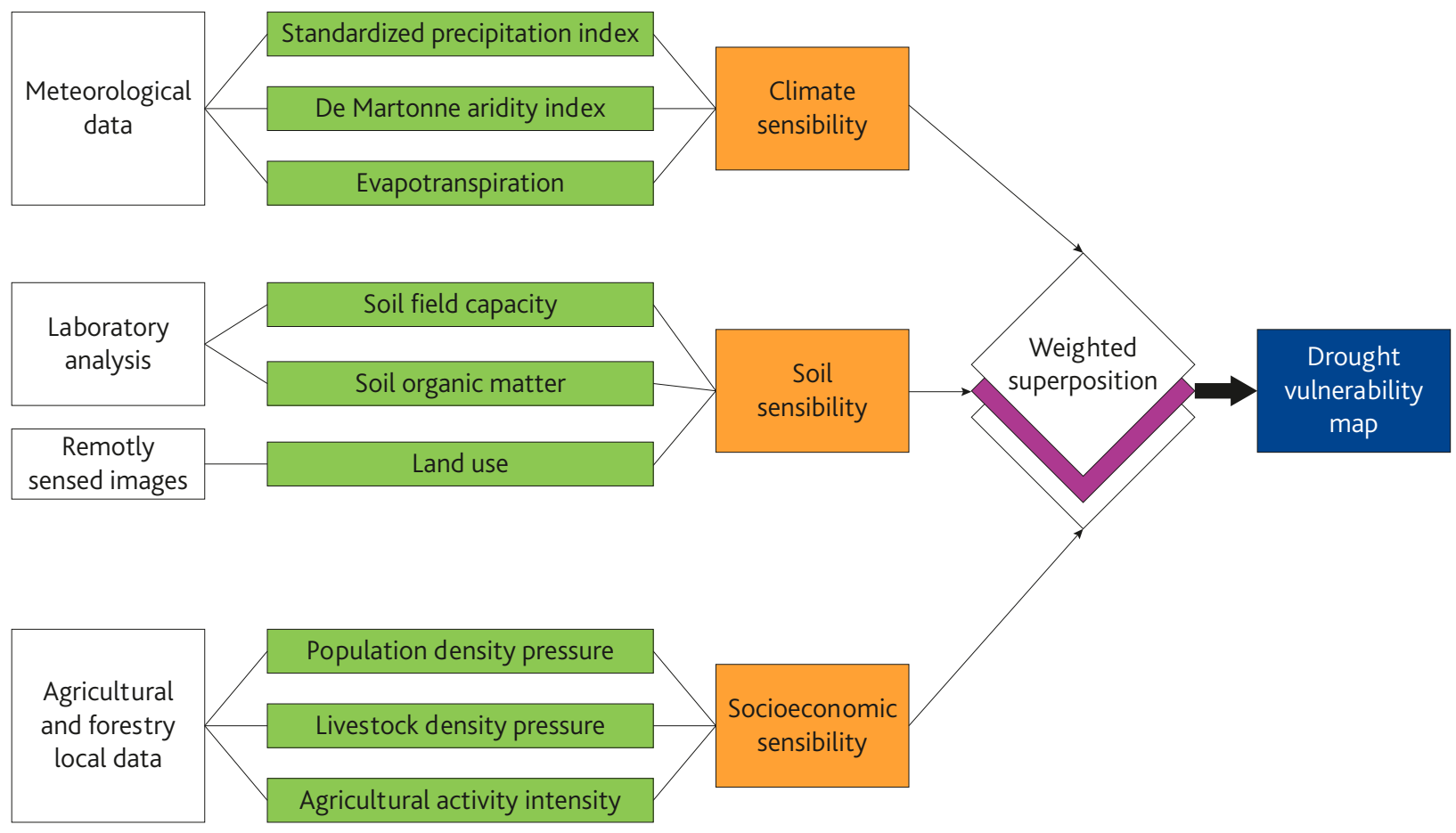

Figure 2. Methodology Chart of the drought vulnerability mapping in the study area 
components that are related to drought : climate, soil and socioeconomic sensitivity using drought-related parameters and indices that are adapted to Mediterranean arid steppes of North Africa with the use of land management expertise weighting and multi-criteria decision making and GIS (Figure.2).

\section{Creating thematic layers}

\section{Climate sensitivity mapping}

The climate factor takes a major part in identifying vulnerable areas to drought, the climatic data used in this study is obtained from rainfall and temperature series provided by two meteorological stations (M'sila and Bousaada), in order to build a climate sensitivity, map we computed the following meteorological indices and parameters:

Standardized precipitation index SPI (Mckee, 1993):

$$
S P I=\frac{\left(P_{i}-P_{m}\right)}{\sigma}
$$

where: $P$ : rainfall in mm per year, $P_{i}:$ Precipitation of year i $P_{m}$ : Average precipitation $\sigma$ : Standard deviation.

De Martonne aridity index (De Martonne, 1926):

$$
A I=\frac{P_{i}}{T_{i}}+10
$$

where $A I=$ aridity index; $P_{i}=$ monthly precipitation amount; $T_{i}=$ monthly mean air temperature

Evapotranspiration (Thornthwaite, 1948):

$$
E T P=16 \frac{10 T}{I}^{a}
$$

where: $T$ : temperature average over 1 year, $I$ : annual thermic index, $a=1.6 \cdot(I / 100)+0.5$

\section{Soil sensitivity mapping}

Soil is one of the largest water storage parts of the climate system, therefore it is important to include it in the drought analysis (Gregorič, 2012). Soil quality has an important part in determining vegetation density and crops' health.

Because of the lack of historic soil maps of the area, the conduction of soil sensitivity layer needed laboratory analysis to define soil properties (water retention and organic matter), Soil samples were taken from randomized circles in 45 sampling points, after removing the litter layer from (o - $20 \mathrm{~cm}$ depth). In laboratory, soil samples were sieved $(<2 \mathrm{~mm})$, then soil retention capacity (holding capacity) was determined from each sample using the "European" maximum water holding capacity, method where a soil sample is saturated with water in a cylinder that is placed on an absorbent membrane until the excess water is drawn away by gravity; once equilibrium is reached, the water holding capacity is calculated based on the weight of the water held in the sample comparing to the sample dry weight.

Organic matter was defined in laboratory using the Walkley-Black titration method (Walkley, Black, 1939). The analysis results were mapped using GIS (spatial interpolation tool) where data was interpolated spatially from each sample point using the IDW interpolation tool in ArcGIS 10.2.2 software.

The land use map is obtained after field sampling and observation followed by a using the ENVI 5.3 software for a supervised classification of a satellite image from Landsat Satellite (Oli Captor) of the date: 09 March 2016 provided by the USGS earth explorer.

\section{Socioeconomic sensitivity mapping}

Socioeconomic statistics are provided by forests conservation directorate and agricultural and rural development directorate of M'sila province. Data was processed and entered into a GIS database and interpolated spatially using the IDW interpolation tool in ArcGIS 10.2.2 software

\section{Drought vulnerability final mapping}

Sub criteria mapping and scores assigning

At first, all indices and parameters were mapped to form sub criteria layers that will enter in our final drought vulnerability assessment (Figure.3).

The next step is to reclassify each sub-criteria layer into value intervals using ArcGIS reclassifying tool (Table 3), then, scores from 1 to 7 were assigned to each class, where 1 stands for a favorable value class, for example entering 1 as a score for a class of values that range

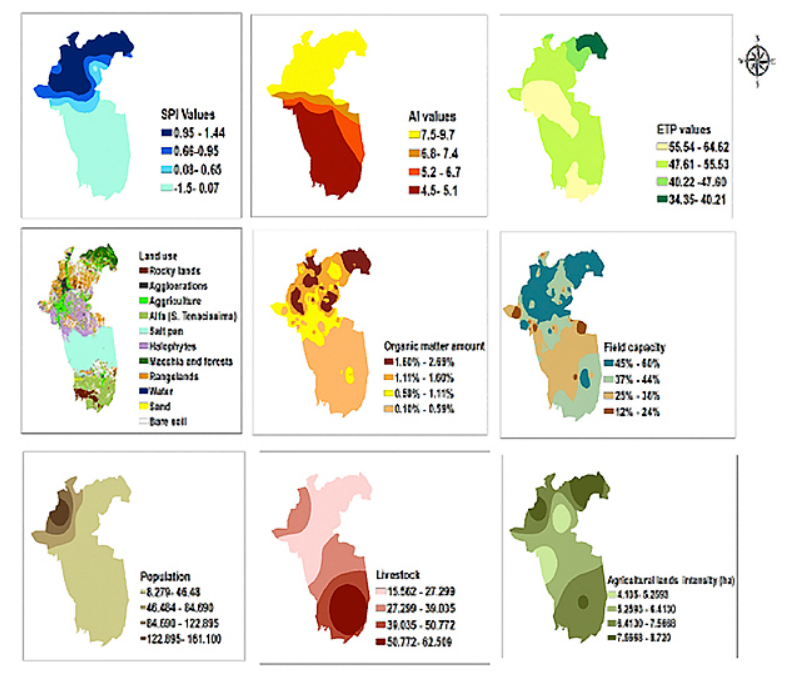

Figure3. Parameters and indices maps 
Table3. Scores assigning

\begin{tabular}{|c|c|c|c|}
\hline Factors & $\begin{array}{l}\text { Parameters } \\
\text { and indices }\end{array}$ & Values & Scores \\
\hline \multirow{12}{*}{ 离 } & \multirow{4}{*}{$\begin{array}{l}\text { Standardized } \\
\text { precipitation } \\
\text { index }\end{array}$} & $0.95-1.44$ & 1 \\
\hline & & $0.66-0.95$ & 2 \\
\hline & & $0.08-0.65$ & 3 \\
\hline & & $-1.5-0.07$ & 4 \\
\hline & \multirow{4}{*}{$\begin{array}{l}\text { Demartonne } \\
\text { Aridity index }\end{array}$} & $7.5-9.7$ & 1 \\
\hline & & $6.8-7.4$ & 2 \\
\hline & & $5.2-6.7$ & 3 \\
\hline & & $4.5-5.1$ & 4 \\
\hline & \multirow{4}{*}{$\begin{array}{l}\text { Evapotranspira- } \\
\text { tion }\end{array}$} & $34.35-40.21$ & 1 \\
\hline & & $40.22-47.60$ & 2 \\
\hline & & $47.61-55.53$ & 3 \\
\hline & & $55.54-64.62$ & 4 \\
\hline \multirow{19}{*}{ "̄ं } & \multirow{4}{*}{$\begin{array}{l}\text { Soil Field } \\
\text { Capacity }\end{array}$} & $12 \%-24 \%$ & 1 \\
\hline & & $25 \%-36 \%$ & 2 \\
\hline & & $37 \%-44 \%$ & 3 \\
\hline & & $45 \%-60 \%$ & 4 \\
\hline & \multirow{4}{*}{$\begin{array}{l}\text { Soil organic } \\
\text { matter }\end{array}$} & $1.60 \%-2.69 \%$ & 1 \\
\hline & & $1.11 \%-1.60 \%$ & 2 \\
\hline & & $0.59 \%-1.11 \%$ & 3 \\
\hline & & $0.10 \%-0.59 \%$ & 4 \\
\hline & \multirow{11}{*}{ Land use } & Water & 1 \\
\hline & & Macchia and forests & 2 \\
\hline & & Agricultural lands & 2 \\
\hline & & Rocky outcrops & 3 \\
\hline & & Agglomerations & 3 \\
\hline & & Salt pan & 4 \\
\hline & & Alfa steppes & 5 \\
\hline & & Halophytes & 6 \\
\hline & & Rangelands & 5 \\
\hline & & Sand dunes & 4 \\
\hline & & Bare soil & 7 \\
\hline \multirow{12}{*}{ 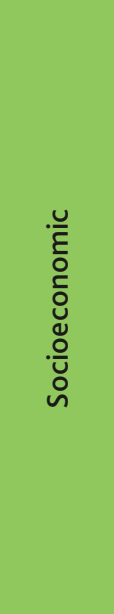 } & \multirow{4}{*}{$\begin{array}{l}\text { Population } \\
\text { Density pressure }\end{array}$} & $8.279-46.48$ & 1 \\
\hline & & $46.484-84.690$ & 2 \\
\hline & & $84.690-122.8956$ & 3 \\
\hline & & $122.895-161.100$ & 4 \\
\hline & \multirow{4}{*}{$\begin{array}{l}\text { Livestock Density } \\
\text { pressure }\end{array}$} & $15.562-27.29$ & 1 \\
\hline & & $27.299-39.035$ & 2 \\
\hline & & $39.035-50.772$ & 3 \\
\hline & & $50.772-62.509$ & 4 \\
\hline & \multirow{4}{*}{$\begin{array}{l}\text { Agricultural } \\
\text { activity intensity }\end{array}$} & $4.1056-5.2593$ & 1 \\
\hline & & $5.2593-6.4130$ & 2 \\
\hline & & $6.4130-7.5668$ & 3 \\
\hline & & $7.5668-8.720$ & 4 \\
\hline
\end{tabular}

between 0.95 and 1.44 means that this class is more climatically suitable than the class where values range between 0.07 and -1.5 to which a score of 4 is given.

\section{Multicriteria decision making}

Multi-criteria decision-making method is a branch of a general class of operations research models that is suitable for addressing complex problems featuring high uncertainty, conflicting objectives, different forms of data and information, multi interests and perspectives, and the accounting for complex and evolving biophysical and socio-economic systems (Wang, et al., 2010).

This method was developed by Thomas Saaty in the 1970 s and is based on mathematics and psychology (Saaty, 1980). It is used in managerial decision-making field, in summary, a decision-maker must "weigh" several options before deciding on one of them taking into account a series of criteria that he considers more or less essential to be respected (Cissokho, 2011).

The first step is to form a series of comparison by pairing these criteria according to their relative importance and their influence in drought hazard, we use a scale of numbers that indicate how many times more important or dominant one element is over another one, values of this scale range between 1 and 9 (Saaty, 1980). For example, entering 3 in the climate -soil position means that climate factor is three times more important and influencing drought in the study area than soil factor, and entering 1 in climate- socioeconomic stress position means that both factors are equally important (Table 2).

Table 4. Assigned weight according to Saaty scale

\begin{tabular}{|l|c|c|c|}
\hline Criterion & Climate & $\begin{array}{c}\text { Socioeconomic } \\
\text { stress }\end{array}$ & Soil \\
\hline Climate & 1 & 3 & 5 \\
\hline $\begin{array}{l}\text { Socioeconomic } \\
\text { pressure }\end{array}$ & $1 / 3$ & 1 & 3 \\
\hline Soil & $1 / 5$ & $1 / 3$ & 1 \\
\hline
\end{tabular}

The second step is to calculate the eigenvector (Vp) which is determined by calculating the geometric mean for each criterion, after that, the weighting coefficient for each criterion is deduced by dividing each eigenvector by their sum, the sum of the weighting coefficients must be equal to 1 (Table 3 ).

Table 5. Weighting coefficients

\begin{tabular}{|l|c|}
\hline Criteria & Weight \\
\hline Climate criterion & 0.6333 \\
\hline Anthropic pressure criterion & 0.1062 \\
\hline Soil criterion & 0.2605 \\
\hline Sum & 1 \\
\hline
\end{tabular}




\section{Results and discussion}

\section{Layer mapping}

The final step is to aggregate and compile climate, soil and socioeconomic sensitivity layers to build the final vulnerability map using weighed sum method (Weighted sum tool in ArcgGIS 10.2.2) where each layer is divided by its calculated weight.

\section{Climate sensitivity}

Not sensitive areas form $37.61 \%$ of the study area, located mainly on Maadhid Mountains in the North $(1,200-1,900 \mathrm{~m}$ a.s.l), and on agricultural lands in M'sila and M'tarfa.

Slightly and moderately sensitive areas from respectively $2.66 \%$ and $35.70 \%$ located on the peripheries of the salt pan, where the altitudes vary between 400 and $440 \mathrm{~m}$ a.s.l.

Sensitive and very sensitive areas form $21.93 \%$ and $2.08 \%$ mainly located on lower altitudes of the plains of M'cif and Souaamaa.

\section{Soil sensitivity}

Not sensitive areas constitute $22.55 \%$ of the total surface dominated by agricultural lands and mountainous regions covered by green oak stands, and Aleppo pine forests, the permanent irrigation of agricultural lands and the regular precipitation distribution on mountains provide a favorable soil quality for vegetation cover and crops in these areas.

Slightly and moderately sensitive areas form $16.10 \%$ and $23.27 \%$ respectively, distributed on rangelands, abandoned fields and Alfa steppes (stippa tencissima).
Sensitive areas form $6.24 \%$ distributed on the salt pan surface, halophytes and spontaneous plants fields.

Very sensitive areas form $31.82 \%$ mainly located on bare and sandy soils where humidity and water retention is very low.

\section{Socioeconomic sensitivity}

The degree of socioeconomic sensitivity decreases away from urban agglomeration and industrial zones; not sensitive areas form $18.56 \%$ of the total surface, located on M'tarfa plains and on parts of the salt pan of El Hodna.

Slightly and moderately sensitive areas form respectively $39.91 \%$ and $32.11 \%$ located on the peripheries of urban agglomeration.

Sensitive and very sensitive areas form $3.21 \%$ and $6.10 \%$ are located on urban agglomerations mainly the city of M'sila (80o,0oo inhabitants).

\section{Drought Vulnerability Mapping}

Final drought mapping is also classified according to pixel values into five vulnerability classes (Figure 5).

Not vulnerable regions form $21.37 \%$ of the study area, located mainly on mountains $(1,293 \mathrm{~m}$ to $1,859 \mathrm{~m}$ a.s.l) where the soil is humid and less exposed (Northern aspect), and on agricultural lands where the vegetation cover is denser and irrigated permanently, which makes of this region a favorable biotope, having the privilege of elevated rainfall rates, and also of being distant from human and livestock pressure, and road network (Figure 6)

Slightly vulnerable areas form $16.28 \%$ of the surface and located mainly on southern mountainsides

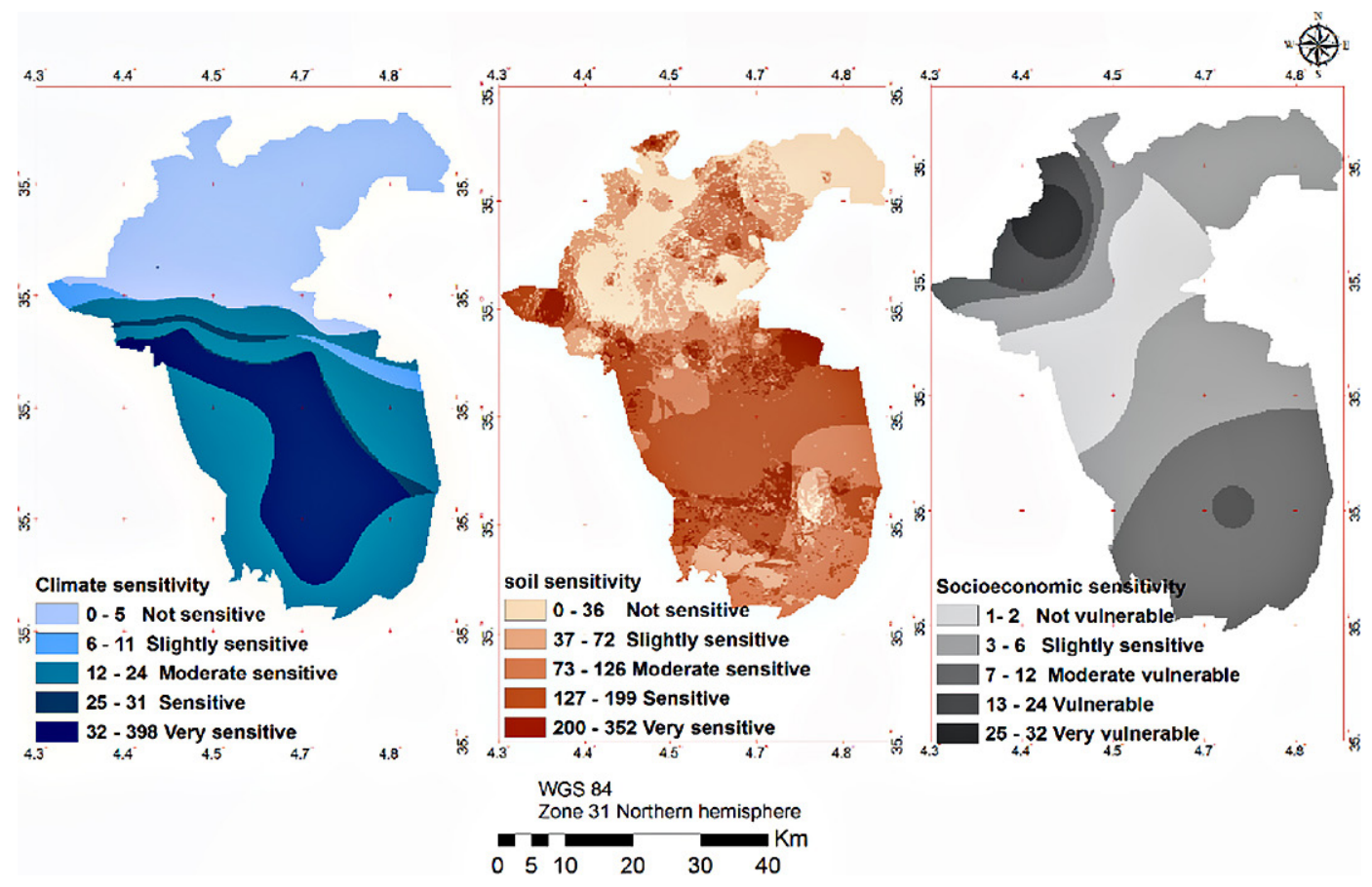

Figure 4. Climate, soil and socioeconomic sensitivity maps 


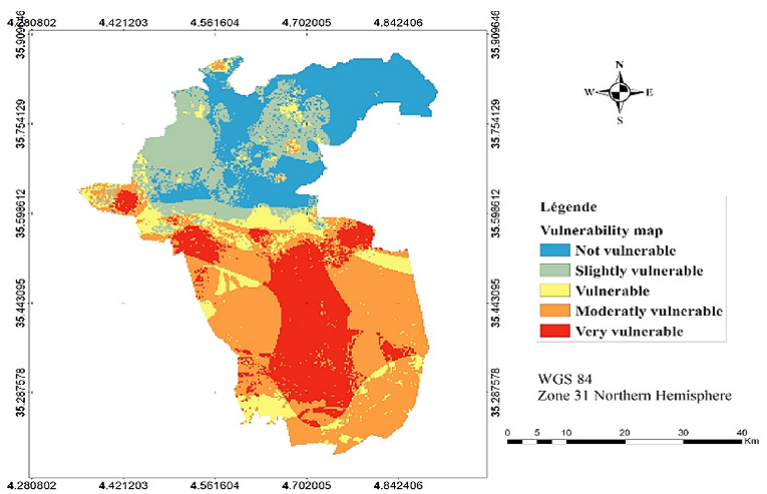

Figure 5. Final vulnerability map

and on the peripheries of agricultural that exigently require permanent water supplies which exacerbates the pressure and the overuse of water reserves.

Moderately vulnerable areas form $10.06 \%$ of surface and are located on rocky outcrops, rangelands and abandoned fields reserved for livestock grazing which leads to a land degradation (Figure 7).

Vulnerable and very vulnerable areas form respectively $32.81 \%$ and $19.46 \%$ of the total surface, distributed on the rest of the study zone covering bare and sandy soils with southern aspect, and also the salt pan. The rainfall average in these areas is lower than $200 \mathrm{~mm}$ per year with sparse and rare vegetation cover (Figure 8).

The vast vulnerable and very vulnerable land surface notably in the south of the study area hypothecates that vulnerability situation will be aggravated in the future, especially with the decreasing of rainfall quantities and the tendency to scarcity reported by precipitation data of the last decades (Medjerab, Henia, 2011).

The combination of water supplies diminution with the poor quality of soil, the sparseness of vegetation cover, erosion, and the increasing of socioeconomic pressure; will exacerbate the drought vulnerability of the study area; areas that are classified as moderately vulnerable are tendentious to become vulnerable and/ or very vulnerable. This tendency threatens the environmental situation of forests and agricultural lands leading to an overuse of water for irrigation which jeopardizes water and food security and transforming large steppes into bare soils.

In Algeria, arid and semi-arid environments' monitoring is based generally on thematic maps, field missions and classic methods, these operations take long durations of time, and absorb large disbursement especially in vast areas (Bensaid, 2006), many studies were conducted to assess environmental risks in arid lands such as erosion and desertification while drought still remains quit an unstudied hazard, studies were conducted on a regional scale such as Yasef and Saltani study (2009) (Sahara and Sahel observatory), or by reviewing climatic indices.
Bensaid (2006) and Bouzekri (2015), have conducted similar studies on others regions of Algerian arid steppes (the region of Naama and the Aures respectively) and they found that steppes reserved for grazing are more vulnerable to natural hazards such as desertification, sand invasion and wind erosion, in the case of our study agricultural lands are also potentially vulnerable besides steppes and rangelands.

After building the vulnerability final map, field missions were performed to validate the results and to verify the adequacy of our methodology as well as to identify and propose appropriate management plans and solution for drought mitigation.

Several management plans may be considered for application in this area to alleviate the impact of drought, such as planting trees around farms and agricultural lands to form natural barriers against wind erosion and sand storms. Other ways to alleviate the impact include planting shrubs and turf to limit soil evaporation and moisture loss

Drought mitigation is strongly related to the preservation of water resources (dams, reservoirs, underground water), also collecting precipitation water for immediate or eventual use in irrigation or domestic activities may be considered as a solution to minimize the pressure on underground water.

Due to the use of saline water for irrigation, salt levels are very elevated in agricultural lands and appear as a white layer on the surface (Figure 7); and for this, land reclamation is required to minimize salt amount in these soils. Reducing the salt amount is accomplished by disposing the accumulated salt on the surfaces, and improving chemical and biological soil properties through leaching and drainage operations with adding amendments and calcium supplies to reduce salt concentration in soil depths which will allow plants' roots to grow, also it is important to select salt-tolerant crops at the beginning of reclamation.

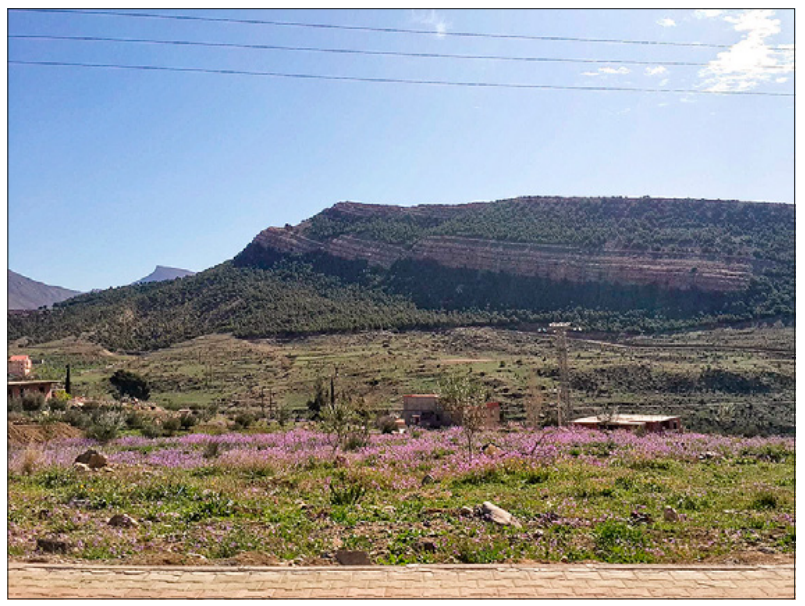

Figure 6. Not affected area region of Maadhid mountains 


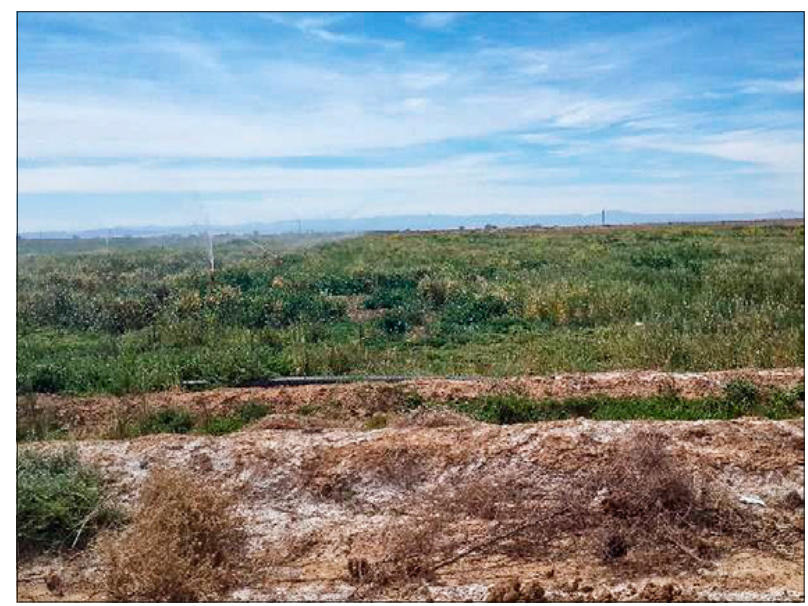

Figure 7. Agricultural lands of the region of M'sila

\section{Conclusions}

Vulnerability mapping of different natural hazards is very important to both predict and prepare for a natural disaster's response, it allows to decision makers and users to have spatiotemporal information about the extent and the duration of different natural hazards. This study presented a contribution to drought vulnerability mapping, the aim of this study is to compile climate, soil and socioeconomic data using a GISbased model adapted to dry lands and developed from two previous drought assessment models: a DMCSEE model (drought management center of southeastern Europe) and an OSS model (Observatory of Sahara and Sahel), with the integration of multicriteria analysis tool for decision making. This methodology uses available and simple data to facilitate drought assessment and monitoring to users and researchers.

The results show that very vulnerable and vulnerable areas form respectively $19.46 \%$ and $32.81 \%$ of the total surface, slightly vulnerable form $16.28 \%$, moderately vulnerable form $10.06 \%$ and not vulnerable areas form $21.37 \%$, the decreasing of water supplies and rainfall rates with the increasing of socioeconomic pressure may exacerbate the vulnerability situation and cause the expanding of vulnerable and very vulnerable areas.

\section{References}

Bensaid, A. 2006. GIS and remote sensing for the study of silting in an arid zone: The case of the wilaya of Naama. Doctoral Thesis. University of Grenoble, France 10-14 pp. (in French with English summary). Bouzekri, A. 2015. Multicriteria evaluation of critical situations to desertification risk in Aurès, Territory Management. Doctoral thesis. El hadj lakhdra university Batna, Algeria, 167-168 pp. (in French with English summary)

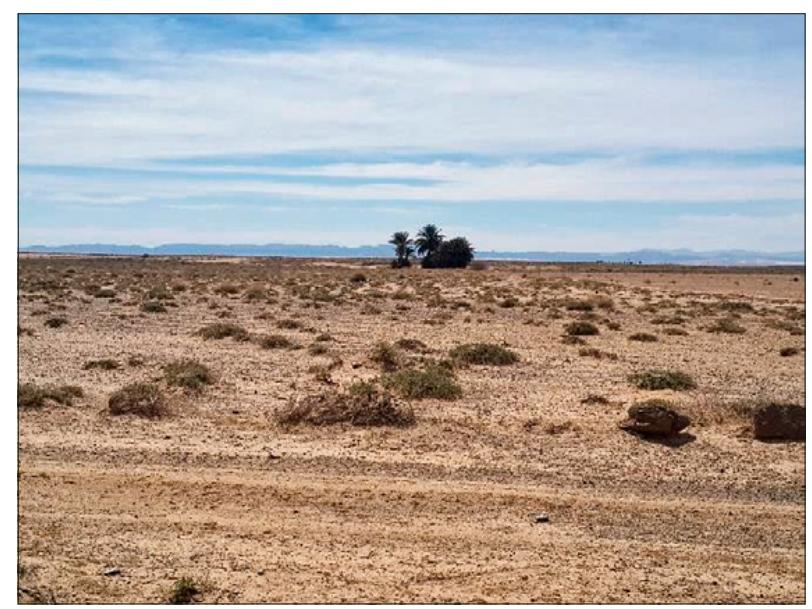

Figure 8. Rangelands and abondoned fields

Cissokho, R. 2011. Développement d'un indice de vulnérabilité à l'érosion éolienne à partir des images satellitaires dans le bassin arachidier du Sénégal: Cas de la région de thies, Doctoral thesis. University of Montreal, Canada, 128-132 pp.

Clark, S. C. 1996. Mediterranean ecology and an ecological synthesis of the field sites. Mediterranean desertification and land use. In: Manual on key indicators of desertification and mapping environmentally sensitive areas to desertification. European Commission Community Research, EUR 1888, $23 \mathrm{pp}$.

Dai, A. 2011. Drought under global warming: a review. Wiley Interdisciplinary. Climatic Change 2-1, 45-65.

Dracup, J. A., Lee, K. S., Paulson, E. G. 1980. On the definition of droughts. Water resources research 16 2, 297-302.

Gregorič, G. 2012. Implementation of drought monitoring in DMCSEE. Summary of project results. Management Centre for South-East Europe - DMCSEE, $10 \mathrm{pp}$.

Houghton, J. T., Ding, Y., Griggs, D. J. 2001. Climate Change. The Scientific Basis. Cambridge University Press, Cambridge.

Layelmam, M. 2008. Calculation of drought indicators from NOAA / AVHRR images. Project to Establish an Early Warning System for Drought in three countries on the southern shore of the Mediterranean: Algeria, Morocco and Tunisia, LIFEo5 TCY/TN/ooo150:6. (in French with English summary)

McKee, T. B., Doesken, N. J., Kleist, J. 1993. The relationship of drought frequency and duration to time scales. Proceedings from Eighth Conference on Applied Climatology, American Meteorology Society,179-184 pp.

Medjereb, A., Henia, L. 2011. Spatio-temporal variation of climate drought in North-Western Algeria. 
Courrier du Savoir 11, 71-79. (in French with English summary)

Móring, A., Németh, A., Bihari, Z., 2012. Estimation and mapping of drought vulnerability on the basis of climate, land use and soil parameters using GIS techniques. Final conference of DMCSEE project, Ljubljana.

Nadjraoui, D. 2011. Steppe Ecosystems vulnerability in Algeria. Proceeding of international conference on Climatic change effect on breeding and sustainable managment of rangelands in the arid and semi-arid zones of the Maghreb, Ouergla, Algeria, 41- $53 \mathrm{pp}$. (in French with English summary)

Nichane, M., Khelil, M. 2014. Climate change and water resources in Algeria, vulnerability, impact and adaptation strategies. Revue des Bioressources 2, 2. (in French with English summary)

Saaty, T. 1980. The Analytic Hierarchy Process: Planning, Priority Setting, Resource Allocation. McGraw Hill International, New York, 287 pp.

Safar Zitoun, M. 2006. Evaluation of existing drought early warning systems at national level: Case of Algeria. Establishment of an early warning system for drought in 3 countries on the southern shore of the Mediterranean: Algeria, Morocco and Tunisia. Oservatoir du Sahara et du Sahel 82, 5-6 pp. (in French with English summary)

Thorntwaite, C. W. 1948. An approach toward a rational classification of climate. The geographical review 38-1, 55-94.

Lohmann, U., Sausen, R., Bengtsson, L., Cubasch, U., Perlwitz, J., Roeckner, E. 1993. The Köppen climate classification as a diagnostic tool for general circulation models. Climate Research, 177-193.

Walkley, A., Black, I. A. 1934. An examination of Degtjareff method for determining soil organic matter and a proposed modification of the chromic acid titration method. Soil Science 37-1, 29-37.

Wang, J. J., Jing, Y. Y., Zhang, C. F., Zhao, J. H. 2009. Review on multi-criteria decision analysis aid in sustainable energy decision-making. Renewable and Sustainable Energy Reviews,13-9, 2263-2278.

Wilhite, D. A. [ed.]. 2005. Drought and water crises: science, technology, and management issues. CRC Press, Boca Raton, 7-9 pp.

Wilhite, D. A., Glantz, M. H. 1985. Understanding: the drought phenomenon: the role of definitions. $\mathrm{Wa}$ ter international 10-3, 111-120.

WMO. 2006. Drought Monitoring and Early Warning: Concepts, Progress and Future Challenges. World Meteorological Organization 1006, 24 pp.

Yasef, M., Saltani, Z. 2009. Synthesis of zoning: final report. Establishment of an early warning system for drought in 3 countries on the southern shore of the Mediterranean: Algeria, Morocco and Tunisia. Oservatoir du Sahara et du Sahel, 2-4 pp.

\section{Other sources}

DMCSEE : http://www.dmcsee.org/en/drought_monitor/

OSS: http://www.oss-online.org/

USGS earth explorer : https://earthexplorer.usgs.gov/ 